\title{
Direct Comparisons: Resurrecting the Direct Analysis of Phrasal Comparatives
}

\author{
Rajesh Bhatt \\ University of Massachusetts, Amherst University of Massachusetts, Amherst \\ University of Tokyo, JSPS
}

\section{Introduction}

There have been two major strands in the analysis of phrasal comparatives: Reduction Analyses that relate the than-phrase to a degree description denoting clause and Direct Analyses that interpret the than-phrase directly. Reduction Analyses assume that the than-phrase is part of a larger clausal constituent to which reduction operations have applied. Direct Analyses, on the other hand, need to assume a new lexical entry for the degree operator. Based on evidence from binding and scope, we show that the Reduction Analysis is not an option for phrasal comparative in Hindi-Urdu. Their proper analysis requires the Direct Analysis and the 3 -place degree operator that goes with it. Handling other comparatives in HindiUrdu requires the more standard 2-place degree operator. However, as Lechner (2001, 2004) has shown, English and German phrasal comparatives require a Reduction Analysis. This means that both Reduction and Direct Analyses, as well as 2-place and 3-place degree operators are options permitted by universal grammar but that languages vary in which of these options they instantiate. We show that the availability of these options in a particular language follows from independent properties of the language in question and assumptions about when new lexical entries are induced.

\section{The Inventory of Lexical Items}

It has been observed that a wide range of syntactic constituents can appear in the complement of than. The complements of than can denote a range of meanings. Since the than-phrase is a semantic argument of the degree operator, this has implications for the semantics of the degree operator -er. How many meanings do we need for $-e r$ ? How many distinct meanings are attested crosslinguistically?

We would like to thank audiences at the UMass Syntax Reading Group, Ohio State University, GLOW XXX at CASTL Tromsø, McGill University, the XTAG Group at the University of Pennsylvania, SALT 17 at UConn, Fukuoka University, and Kanda University of International Studies for comments and suggestions. In particular, we would like to thank Jeremy Hartman, Kyle Johnson, Winfried Lechner, Roumi Pancheva, Carl Pollard, Bernhard Schwarz, and Lisa Travis. Danny Fox and Jason Merchant gave us comments on a draft of this paper for which we are especially grateful. The second author is supported by the Research Fellowship of the Japan Society for the Promotion of Science (JSPS) for Young Scientists under Grant No. 9919. 


\subsection{2-place -er and Clausal Comparatives}

To address this issue, let us first consider comparatives like (1) in which a degree description appears in the complement of than.

(1) a. John is taller than six feet.

b. Hindi-Urdu:

Atif-ne tiin-se zyaadaa kitaabẽ khariid-ii thĩ:

Atif-Erg three-than more books.f buy-Pfv.f be.Pst.FPl

'Atif bought more than three books.'

We can handle (1) by assigning -er the semantics in (2). According to this lexical entry, -er combines with two degree predicates. Therefore we will refer to this lexical entry as 2-place -er.

$$
\llbracket \text {-er } \rrbracket=\lambda P_{d t} \cdot \lambda Q_{d t} \cdot \exists d[Q(d) \wedge \neg P(d)]
$$

Assuming that gradable adjectives, such as tall, denote a function of type $\langle d,\langle e, t\rangle\rangle$, as in (3), a syntactic constituent that functions as the second argument of the 2-place $-e r$ is created by Quantifier Raising (QR) of $-e r$, as illustrated in (4). ${ }^{1}$

(4) $\quad[[-e r[$ than 6 feet $]][\lambda d$. [John is $d$-tall $]]]$

In addition to degree descriptions, than can also take a clausal structure, as in (5a) (clausal comparatives). ${ }^{2}$ It would be desirable if we could handle clausal comparatives with the independently needed 2-place -er. Indeed, it is widely considered that this is possible. We can assume that the complement of than in clausal comparatives also denotes a predicate of degrees, given several well-motivated assumptions: a than-phrase involves a gradable predicate, which is deleted under identity with one in the matrix clause, and the degree argument of the silent gradable predicate is abstracted over, due to operator movement.

a. John is taller than [Bill is].

b. [[-er [than [OP $\lambda d_{1}$. [Bill is tall]]] [ $\lambda d_{2}$. [John is $d_{2}$-tall]]]

We have seen that the 2-place -er can combine with two types of syntactic constituents, both of which denote a predicate of degrees. There are also cases where -er combines with a constituent that is not a predicate of degrees suggesting the need for another lexical entry. We turn to such cases in the next section.

\footnotetext{
${ }^{1}$ For simplicity, we assume that 6 feet is ambiguous between a degree name (as in John is 6 feet tall) and a predicate of degrees. See Pancheva (2007) for an alternative.

${ }^{2}$ In Hindi-Urdu, a clausal structure cannot appear in the complement of -se 'than' for a reason to which we will return. Instead, correlatives must be used to express clausal comparatives, as in (i).

(i) [Bill jitnaa lambaa hai] [John us-se zyaadaa lambaa hai]

Bill how tall is John that-than more tall is 'John is taller than Bill is.'
} 


\subsection{3-place -er and Phrasal Comparatives}

Phrasal comparatives, exemplified in (6), raise an interesting question for the semantics of the degree operator because only an individual type element is present in the complement of than. Moreoever there is no clear evidence for clausal structure. Consequently, on the surface, the degree operator does not combine with a predicate of degrees.
a. John is taller than Bill.
b. John Bill-se zyaadaa lambaa hai
John Bill-than more tall is
'John is taller than Bill.'

However, it is certainly possible to pursue the hypothesis that the 2-place -er is also at work in phrasal comparatives. Under this approach, a silent clausal structure must be posited in the complement of than, just like in clausal comparatives, and a bigger constituent is assumed to be deleted in phrasal comparatives than in clausal ones (Reduction Analyses, see Lechner 2001, 2004, Merchant 2006, and Pancheva 2006, 2007 among others). One advantage of Reduction Analyses is obvious: we can maintain the simplest lexical inventory in which there is only one lexical entry for the degree operator.

$$
\text { [[-er [than [OP } \lambda d_{1} \text {. [Bill } 1 \lambda d_{2} \text {. [John is } d_{2} \text {-tall]]] }
$$

However, there is another approach to phrasal comparatives, which does not posit any silent structure, but postulates another lexical entry for the degree operator. Under this view, the degree operator can directly take an argument of type $e$ (Direct Analyses, see Heim 1985 for detailed discussion). One lexical entry of -er that makes this possible is provided in (8), in which it needs to take two individuals and one predicate of individuals and degrees as its arguments (the 3-place -er).

$$
\llbracket \text {-er } \rrbracket=\lambda x \cdot \lambda P_{\text {det }} \cdot \lambda y \cdot \exists d[P(y, d) \wedge \neg P(x, d)]
$$

The predicate of individuals and degrees is created by movement of the associate and the degree operator, as illustrated in (9). We assume that first the associate moves creating a syntactic constituent that is a predicate of individuals. The degree operator and the than-phrase form a constituent, which undergoes QR, "tucking-in" beneath the moved associate (Richards 1997). ${ }^{3,4}$

$$
\begin{aligned}
& \text { a. John is taller than Bill. } \\
& \text { [John [[-er [than Bill]] [ } \lambda d . \lambda x \text {. [x is } d \text {-tall] }]]]
\end{aligned}
$$

\footnotetext{
${ }^{3}$ Locality constraints apply to the (covert) movement of the associate as noted in Heim (1985). Relevant examples are *I spent more time with a woman who played the clarinet than the lute (from Heim 1985) and *More people live in the country that Bush governs than Putin (from Merchant 2006). Reduction Analyses are also able to handle these facts.

${ }^{4}$ The effect of syntactic ellipsis in Reduction Analyses is obtained in the Direct Analysis by making use of a predicate of individuals and degrees twice in semantics. Thus, the Direct Analysis can be regarded as a semantic ellipsis approach. See Heim (2000) for further discussion.
} 
b. More students read LGB than the MP.

[LGB [[-er [than the MP]] $[\lambda d . \lambda x$. [ $d$-many students read $x]]]]$

We have seen that the 2-place -er must be assumed independently of phrasal comparatives. Combined with an ellipsis operation, it can successfully deal with phrasal comparatives. Is there any evidence which requires the 3-place-er, as well? Lechner $(2001,2004)$ argues that there is no such evidence at least in English (and German). In fact, Lechner makes the stronger claim that the Direct Analysis (and hence, the 3-place -er) should not be available for English and all phrasal comparatives must be derived from their clausal source by reduction operations. Lechner's claim is based on the analysis of Pinkham's contrast and the binding properties of subjects in phrasal comparatives. We believe that these arguments are not conclusive. However, a natural extension of Lechner's binding data provides a conclusive argument against the availability of the Direct Analysis in English and it is this set of facts that we turn to in the next section. On the basis of these facts, we conclude, in accordance with Lechner, that the 3-place -er is not available in English. We then turn our attention to Hindi-Urdu which we argue provides evidence for a Direct Analysis and the 3-place -er. Languages, then, vary in their lexical inventories with respect to degree operators and we consider some implications of this fact for a theory of crosslinguistic variation in the final section.

\section{Ruling out the Direct Analysis in English}

The following generalization emerges from Lechner's (2004) discussion of the binding properties of phrasal comparatives.

(10) The Phrasal Comparative Binding Generalization:

The remnant is c-commanded by everything that c-commands the associate.

This generalization is exemplified by the binding facts in (11) and (12). ${ }^{5}$ To illustrate the generalization, let us consider (11). In (11a), the pronoun c-commands the associate and cannot corefer with a name within the remnant suggesting that it also c-commands the remnant. In (11c), the associate is not c-commanded by the pronoun and the pronoun can corefer within the remnant suggesting that it does not c-command the remnant. The generalization also receives support from the Condition A data in (11d) and (12c).

(11) a. *More people introduced $\operatorname{him}_{i}$ to Sally than to Peter ${ }_{i}$ 's sister.

b. More people introduced Peter $_{i}$ to Sally than to his ${ }_{i}$ sister.

c. ?More people introduced Sally to $\operatorname{him}_{i}$ than Peter $_{i}$ 's sister.

d. More people introduced $\operatorname{him}_{i}$ to Sally than to himself $f_{i}$.

\footnotetext{
${ }^{5}$ These examples are different from the ones considered by Lechner. Lechner's examples involved a pronoun in the subject position but since the subject position always c-commands the remnant, his examples did not make the intended point. To avoid this confound, our examples involve pronouns in non-subject positions.
} 
(12) a. *More people gave $\operatorname{him}_{i}$ a picture of Sally than a picture of Peter ${ }_{i}$ 's sister.

b. More people gave $\operatorname{Peter}_{i}$ a picture of Sally than a picture of his ${ }_{i}$ sister.

c. More people gave $\operatorname{Peter}_{i}$ a picture of Sally than a picture of himself ${ }_{i}$.

(13) shows that the ungrammaticality of (11a) and (12a) cannot be explained by claiming that a direct object and an indirect object always c-command a thanphrase. In both $(13 \mathrm{a}, \mathrm{b})$, the pronoun does not c-command the associate and consonant with the generalization in (10), it can corefer with a name in the remnant.

(13) a. Mary gave $\operatorname{him}_{i}$ more presents than $\mathrm{John}_{i}$ 's mother.

b. Mary gave more presents to $\operatorname{him}_{i}$ than $\mathrm{John}_{i}$ 's mother.

Let us consider how these facts follow under a Reduction Analysis. A Reduction Analysis could yield representations like (14) for (11a,c) respectively.
a. *More people introduced $\operatorname{him}_{i}$ to Sally
[than $\lambda d$. $d$ many people introduced him to $_{i}$ Peter $_{i}{ }^{\prime}$ s sister]
b. ?More people introduced Sally to $\operatorname{him}_{i}$
[than $\lambda d$. d many people introduced Peter ${ }_{i}$ 's sister to himm

The generalization in (10) is captured naturally under such a Reduction Analysis. An associate and a remnant are situated in exactly the same syntactic configuration. This means that whatever c-commands an associate c-commands the remnant and whatever is commanded by the associate is c-commanded by the remnant.

Under the Direct Analysis, the structural relations that hold between the associate and the rest of the matrix clause do not translate into structural relations between the remnant and the rest of the matrix clause. This can be seen in the structural representations that the Direct Analysis would assign to (11a,c) respectively.

$$
\begin{aligned}
& \text { a. [[to Sally] [[-er [than to Peter } \left.\left.{ }_{i} \text { 's sister }\right]\right] \\
& \text { [ } \left.\left.\left.\left.\lambda d . \lambda x \text {. [d-many people introduced } \text { him }_{i} \text { to } x\right]\right]\right]\right] \\
& \text { b. [[Sally] [[-er [than Peter } \left.\left.{ }_{i} \text { 's sister }\right]\right] \\
& \left.\left.\left.\left[\lambda d . \lambda x \text {. [d-many people introduced } x \text { to } \operatorname{him}_{i}\right]\right]\right]\right]
\end{aligned}
$$

Neither representation has the pronoun c-commanding the remnant. This means that the Direct Analysis is insensitive to an aspect of structure that plays a role in determining binding relations in phrasal comparatives. As a result, it does not predict the generalization in (10). Therefore, the Direct Analysis (and accordingly, the 3-place -er) cannot be at work in English. If it was available, the Condition C violations in (11a) and (12a) would not be accounted for.

The generalization in (10) is not quite accurate as stated. This is shown by the acceptability of examples like (16).

(16) a. More people introduced $\operatorname{him}_{i}$ to Sally than to the popstar that Peter $_{i}$ actually wanted to meet. (Carl Pollard p.c.)

b. More people introduced $\operatorname{him}_{i}$ to Sally than to the woman that Peter ${ }_{i}$ likes. 
In $(16 \mathrm{a}, \mathrm{b})$, the pronoun c-commands the associate and yet is able to corefer with a name inside the remnant, contradicting (10). But note that the offending name in $(16 \mathrm{a}, \mathrm{b})$ is contained within an adjunct, a relative clause. What we have here is an instance of the familiar adjunct-argument Condition $\mathrm{C}$ obviation asymmetry. The contrast in (17) supports this characterization.

a. *More people told $\operatorname{him}_{i}$ the rumor that Mary was a thief than the rumor that $\mathrm{John}_{i}$ was a drug addict.

b. More people told $\operatorname{him}_{i}$ their day to day stories than the rumors that $\mathrm{John}_{i}$ actually wanted to hear.

In (17a), the name is contained within a complement and there is no Condition C obviation. But in (17b), like in $(16 \mathrm{a}, \mathrm{b})$, the name is contained within a relative clause adjunct and Condition $\mathrm{C}$ is obviated. The existence of this asymmetry indicates that an analysis along the lines of (14) is incomplete. Other environments where this asymmetry is found involve overt movement of the maximal projection containing the name. This suggests that the remnant in phrasal comparatives also undergoes overt movement followed by elision of the remainder of the than-constituent as in Merchant (2006). With this modification, the facts in (16) and (17) no longer constitute a real counterexample to (10). The adjunct relative can be merged with the remnant after the remnant has moved out of the elided constituent and thus does not have to be in the c-command domain of a pronoun that c-commands the remnant before movement as in Lebeaux (1990). Complements must be merged early and so a name within a complement must be within the c-command domain of any pronoun that c-commands the remnant before movement. ${ }^{6}$

\section{Hindi-Urdu: A Case for the Direct Analysis}

We have seen that the Direct Analysis is unavailable in English and that we need a Reduction Analysis to handle English phrasal comparatives. Now we turn to phrasal comparatives in Hindi-Urdu. We find that the Direct Analysis is available and that it is the Reduction Analysis that is unavailable.

\subsection{Basic Description}

We start with a basic description of phrasal comparatives in Hindi-Urdu. The remnant combines with the postposition -se 'than'. -se-phrases always precedes degree morphology.

\footnotetext{
${ }^{6}$ This is a good place to note that the Condition $\mathrm{C}$ data with phrasal comparatives is fragile. The judgments are not as secure as we would like them to be. In this, it resembles the fragility of the Condition $\mathrm{C}$ data associated with overt wh-movement. Since we are suggesting that remnants undergo overt A-bar movement, this parallel makes sense. But a note of caution is also in order. The binding data constitutes the only argument against the availability of a Direct Analysis in English. If this data turns out to be compromised, so will the argument against the availability of a Direct Analysis in English.
} 
(18) a. associate $>$ remnant $>$ more: ok

Atif-ne Boman-se zyaadaa kitaabẽ parh-ĩ:

Atif-Erg Boman-than more books.f read-Pfv.FPl

'Atif read more books than Boman.'

b. associate $>$ more $>$ remnant: *

*Atif-ne zyaadaa kitaabẽ Boman-se paṛ-ĩ:

Atif-Erg more books Boman-than read-Pfv.FPl

'Atif read more books than Boman.'

As long as the remnant precedes more, there are no further restrictions on the relative order of the associate and the remnant: the remnant may precede the associate and there may be material between the associate and the remnant. This ordering restriction makes sense once we note that the than-phrase is an argument of more and arguments precede their heads in Hindi-Urdu. In its merge configuration, the thanphrase precedes the degree operator. From here the than-phrase can undergo further scrambling to the left allowing for surface non-adjacency between the remnant and the degree operator as well as orders where the remnant precedes the associate.

The associate can be a PP or a DP and have any grammatical function. As (19e) shows, it can even be a temporal adverb as long as it is realized by a DP.

a. associate $=$ nominative subject: $^{7}$

Atif Maya-se (zyaadaa) lambaa hai Atif.M Maya-than more tall.MSg be.Prs.Sg

'Atif is taller than Maya.'

b. associate $=$ ergative subject: $(18)$

c. associate $=$ dative indirect object: ${ }^{8}$

Atif-ne Mina-ko Tina-se zyaadaa tohfe diye Atif-Erg Mina-Dat Tina-than more presents.m give.Pfv.MP1

'Atif gave more presents to Mina than to Tina.'

d. associate $=$ locative

Amrika-me Rus-se zyaadaa log rah-te haiN

America-in Russia-than more people stay-Hab.MSg be.Prs.Pl

'More people live in America than in Russia.'

e. associate $=$ temporal adverb, realized by a DP

Atif-ne aaj kal-se zyaadaa kitaabẽ paṛ-ĩ:

Atif-Erg today yesterday-than more books.f read-Pfv.FPl

'Atif read more books today than yesterday.'

\footnotetext{
${ }^{7}$ The degree head zyaadaa can be covert with a subclass of adjectives, for example with lambaa 'tall', but not with utsuk 'eager'. It must be overtly realized with attributive comparatives.

${ }^{8}$ This example is actually ambiguous in exactly the same way as Atif gave more presents to Mina than Tina i.e. the subject can also be the associate.
} 
But if the remnant is not a DP, the resulting phrasal comparative is not well-formed. This is in contrast to English phrasal comparatives where essentially any phrasal constituent can form the remnant. The adverbials happily and unhappily are not realized by DPs in Hindi-Urdu and consequently the corresponding phrasal comparative in (20b) is ungrammatical.

(20) a. More students read the textbook happily than unhappily.

b. *[khush ho kar] [dukhii ho kar]-se zyaadaa chaatrõ-ne kitaab happy be do sad be do-than more people-Erg book.f parh-i: read-Pfv.f

Intended: 'More students read the textbook happily than unhappily.'

The remnant, which is marked by the postpositional -se, can only be a bare DP. The case marker on the associate cannot appear on the remnant.

a. associate $=$ ergative subject Atif-ne

*Atif-ne Mina-ko Tina-ne-se zyaadaa tohfe diye Atif-Erg Mina-Dat Tina-Erg-than more presents.m give.Pfv.MP1

Intended meaning: 'Atif gave more presents to Mina than Tina.'

b. associate $=$ dative indirect object Mina-ko

*Atif-ne Mina-ko Tina-ko-se zyaadaa tohfe diye Atif-Erg Mina-Dat Tina-Dat-than more presents.m give.Pfv.MP1

Intended meaning: 'Atif gave more presents to Mina than to Tina.'

The ungrammaticality of $(21 a, b)$ fits with the general absence of case stacking in Hindi-Urdu and the fact that postpositions can only combine with DPs.

\subsection{Applying the Direct Analysis to Hindi-Urdu}

Let us consider the application of the Direct Analysis to a concrete example, (19c), repeated below as $(22)$.

Amrika-me Rus-se zyaadaa log rah-te haiN America-in Russia-than more people stay-Hab.MSg be.Prs.P1

'More people live in America than in Russia.'

The degree morphology is located on the subject zyaadaa log 'more people' and the -se-phrase, Rus-se 'Russia-than' precedes the degree morphology. In this example, the associate Amrika-me 'America-in' is a locative semi-argument of the predicate rah 'stay'. The default position of this locative (in a non-comparative) is after the subject but here, it must precede the subject. This precedence restriction is discussed in Section 4.4. The surface word order in (22) is quite close to what we need for interpretation. The associate has moved overtly creating a predicate that can be targeted by the movement of the degree phrase. 
But the associate is a PP. Since Hindi-Urdu does not allow P-stranding, it takes its postposition along with it when it moves. For interpretation, however, we assume that the postposition stays in its base position. ${ }^{9}$ The degree phrase, which consists of the degree head zyaadaa and the -se-phrase, then moves to the edge of the predicate created by the movement of the associate. This yields the desired interpretation.

a. Movement of associate, Pied-piped P is interpreted low:

[[America] $\lambda x$. [[[[Russia-than] more] people] live in $x]]$

b. Degree Phrase moves, tucking-in below Associate:

[[America] [[[Russia-than] more] [ $\lambda d . \lambda x$. [[ $d$-many people] live in $x]]]]$

In the following sections, we present a number of arguments for the availability of the Direct Analysis for Hindi-Urdu phrasal comparatives.

\subsection{The Single Remnant Restriction}

Comparatives in many languages allow for multiple remnants as can be seen in (25a). In contrast, phrasal comparatives in Hindi-Urdu only allow for a single remnant. Multiple remnants are sharply ungrammatical (see 25b). We refer to this property of Hindi-Urdu phrasal comparatives as 'The Single Remnant Restriction'.

a. Tina read more books today than Pim yesterday.

b. *Tina-ne aaj [Pim kal-se] zyaadaa kitaabẽ parh-ĩ:

Tina-Erg today Pim yesterday-than more books.f read-Pfv.FPl

Intended: 'Tina read more books today than Pim yesterday.'

This meaning is conveyed by a clausal structure realized by a correlative. ${ }^{10}$

$$
\begin{aligned}
& \text { [Pim-ne kal jitnii kitaabẽ paṛ-ĩ:] [Tina-ne aaj } \\
& \text { Pim-Erg yesterday how.many.f books.f read-Pfv.FPl Tina-Erg today } \\
& \text { us-se zyaadaa kitaabẽ parh-ĩ:] } \\
& \text { that-than more books read-Pfv.FPl } \\
& \text { 'Tina read more books today than Pim yesterday.' (Literally: 'How many } \\
& \text { books Pim read yesterday, Tina read more books than that today.') }
\end{aligned}
$$

Lechner's Reduction Analysis offers a uniform treatment of comparatives with multiple remnants like (25a) and cases with a single remnant. But under such an analysis the Single Remnant Restriction found in Hindi-Urdu is unexpected. ${ }^{11}$

\footnotetext{
${ }^{9}$ Note that the postposition makes a semantic contribution. This can be seen by the fact that the Hindi-Urdu counterparts of 'More people live on the earth than the moon' and 'More people live in the earth than the moon' have, as one might expect, different meanings.

${ }^{10}$ Note that the main clause of the correlative contains a phrasal comparative. The complement of $-s e$ 'than' is a pronoun that refers to the degree description created by the correlative clause. Since the than-phrase stands for a degree description, we need to use the 2-place -er.

${ }^{11}$ Merchant (2006) provides an alternative analysis of the Single Remnant Restriction which is compatible with the Reduction Analysis. His analysis begins with the observation that there are
} 
The Direct Analysis, however, predicts a Single Remnant Restriction. To see this consider a generalization of the 3-place -er into a $2 n+1$-place -er. Such an -er would combine with $n$ associates, $n$ remnants, and a predicate of $n$ individuals and a degree. For (25a) where we have two associates, $n$ would be two and we would need a 5-place -er. In order to get the relevant arguments in place, we could QR all the associates and move the Deg head. But this does not actually deliver us the LF syntax we need. The remnants are not in the right place. They form a constituent (= than-clause) and -er cannot look into this constituent and extract its arguments. Consequently there is no straightforward way of extending a Direct Analysis based on a 3-place -er to handle multiple remnants.

This is a good result. Multiple remnants are absent in Hindi-Urdu and we take this absence of multiple remnants to show that a Direct Analysis is a viable option for phrasal comparatives in Hindi-Urdu and that a Reduction Analysis of the sort proposed by Lechner is not viable for the Hindi-Urdu data.

We speculate that a Reduction Analysis is ruled out for Hindi-Urdu because of a language particular interaction between the Hindi-Urdu -se, which is a postposition, and finite clauses. The relevant reduction processes that could yield the Reduction Analysis, such as Gapping, seem to be restricted to finite clauses in this language. However, finite clauses can never appear as complements of -se, or for that matter any postpositional element in Hindi-Urdu.

a. John has been happy [since [Mary arrived]].

b. *John [Mary aa-ii hai]-se khush hai

John Mary come-Pfv.f be.Prs.Sg-from happy be.Prs.Sg

Intended: 'John has been happy since Mary arrived.'

To achieve this meaning, a correlative construction must be used where the finite clause complement of the postposition appears as a correlative which is associated with a pronoun that is the complement of the postposition.

[jab-se Mary aa-ii hai] [tab-se John khush hai]. when-from Mary come-Pfv.f be.Prs.Sg then-from John happy be.Prs.Sg

'John has been happy since Mary arrived.'

\subsection{A Precedence Constraint}

An important aspect of the Direct Analysis is that it assumes that there is a configuration in which -er combines with its two individual arguments and a predicate of individuals and degrees.

two kinds of than's in Greek: apo, which only allows for DPs and imposes a Single Remnant Restriction, and apoti, which allows for a much wider range of constituents and does not impose a Single Remnant Restriction. He proposes that with apo, which is a preposition, the remnant moves into the object position of the preposition and it is the nature of the landing site that imposes the Single Remnant Restriction. His explanation is an attractive one for the Greek data but does not extend to the Hindi-Urdu data discussed here. The crucial examples are (19b-d). See also footnote 9. For reasons of space, we cannot go into further details here. 
When the associate is the subject, it is in the right place to combine with -er.

$$
\text { [Subject [[Remnant -er] }[\lambda d . \lambda x \text {. [Pred }(x, d)]]]]
$$

But when the associate is not the subject, it must undergo movement to appear as an argument of -er and thereby create the compared predicate. In a language with covert movement, this movement need not be overt (see 9).

As is well known from the scopal ambiguity of sentences like Some boy likes every girl, surface syntactic scope does not determine scopal relations in English. To derive scopal relations that do not correspond to surface scope, we need covert scope shifting operations. There are several ways of implementing a covert scope shifting operation. A common one is in terms of QR. It has also been noted that there are languages where covert scope shifting operations are either unavailable or very restricted. Hindi-Urdu is such a language as shown by the unavailability of inverse scope in (31a). To get inverse scope, overt scrambling is necessary as shown by (31b) (see Nevins \& Anand 2003 for some qualifications).

a. some > all, unavailable: all $>$ some

kisi larke-ne har tiicar-se aashirvaad liyaa some boy-Erg every teacher-from blessing.m take.Pfv.MSg

'Some boy took blessings from every teacher.'

b. all $>$ some, also available: some $>$ all

har tiicar-se kisi larke-ne aashirvaad liyaa every teacher-from some boy-Erg blessing.m take.Pfv.MSg

'Some boy took blessings from every teacher.'

We take (31) to demonstrate the unavailability of covert QR of DPs in Hindi-Urdu. Given this unavailability, we predict any phrasal comparative where the associate is not in the right position to combine with -er on the surface to be deviant. We also predict that if overt scrambling brings the associate to a position where it can combine with -er, the deviance should disappear. (32) shows that this is the case.

a. remnant $>$ more $>$ associate

*MP-se zyaadaa logõ-ne LGB parh-ii

MP-than more people-Erg LGB.f read-Pfv.f

'More people read LGB than the MP.' (intended, but unavailable) ${ }^{12}$

LF: $*[[$-er than the MP $][\lambda d$. $d$-many people read LGB]]]

\footnotetext{
${ }^{12}$ This sentence is actually grammatical but with a distinctive prosody which groups together $M P$ se 'MP-than' and zyaadaa 'more' and puts a pause between zyaadaa and logõ-ne 'people-Erg'. The interpretation associated with this prosody could be characterized as follows: 'it would be more appropriate to say that people read LGB than to say that people read MP'. We have not worked out the details of how this reading is to be derived but what already seems clear is that this interpretation works off a structure where the zyaadaa 'more' does not form a constituent with the subject or quantify over a degree argument associated with the subject. Support for this comes from the fact that the relevant interpretation is available even when the subject logõ-ne 'people-Erg' is replaced by a non-degree-quantifiable proper name subject.
} 
b. associate $>$ remnant $>$ more

LGB MP-se zyaadaa logõ-ne parh-ii

LGB.f MP-than more people-Erg read-Pfv.f

'More people read LGB than the MP.'

LF: [LGB [[-er than the MP] $[\lambda d . \lambda x$. $[d$-many people read $x]]]]$

The precedence constraint found with Hindi-Urdu phrasal comparatives follows directly from the Direct Analysis combined with the independent unavailability of covert QR in Hindi-Urdu. One implication of the precedence constraint is that associates need to overtly move to the position where -er takes scope. As a result, the locality constraints in Hindi-Urdu phrasal comparatives are just locality constraints on overt movement. This is shown in (33). Relative clauses are islands for overt movement in Hindi-Urdu and an associate cannot move out of a relative clause island to combine with a degree head.

$$
\begin{aligned}
& \text { *[Arundhati-ne }]_{i} \text { Vikram-se zyaadaa log [vo kitaab [jo t }{ }_{i} \\
& \text { Arundhati-Erg Vikram-than more people that book Rel } \\
& \text { likh-ii hai]] parh-ẽ:ge } \\
& \text { write-Pfv.f be.Prs.Sg read-Fut.3MPl }
\end{aligned}
$$

Intended: 'More people will read the book that Arundhati wrote than (the book that) Vikram (wrote).'

\subsection{Binding Effects}

The data from binding effects in English phrasal comparatives was crucial in deciding that the Direct Analysis could not be available in English. With respect to binding, the remnant DP in an English phrasal comparative seemed to have the same possibilities as the associate. This property could be made to follow naturally within a Reduction Analysis but could not be handled within a Direct Analysis. We have argued so far that the Direct Analysis is available in Hindi-Urdu and that the Reduction Analysis is not. Therefore we expect the binding properties of the remnant in Hindi-Urdu phrasal comparatives to be different from English. In particular, we do not expect there to be a connection between the binding possibilities of the associate and the binding possibilities of the remnant.

According to the Direct Analysis, the remnant is a PP and thus we expect it to pattern with other PPs with respect to binding properties. This turns out to be the case. The binding properties of PPs in Hindi-Urdu are as follows:

(34) a. Subjects can bind reflexives and reflexive possessors inside PPs. Pronominal possessors inside PPs cannot be coreferent with the subject.

b. PPs pattern with arguments with respect to Principle B.

c. Co-arguments that precede the PP c-command it and the PP c-commands co-arguments that follow it. 
The than-phrase in Hindi-Urdu has exactly the binding properties outlined above. We demonstrate some of these properties here. Pronominal than-phrases as well as pronominal possessors inside than-phrases display obviation with respect to the subject. To achieve binding with the subject, an anaphor must be used.

a. anaphoric binding, pronominal obviation by subject:

koi-bhii ${ }_{i}$ apne aap-se ${ }_{i} /$ us-se $_{j / * i}$ lambaa nahĩ: ho sak-taa anyone self's self-than/him-than tall Neg be can-Hab.MSg

'No one ${ }_{i}$ can be taller than himself $/$ him $_{j / * i}$ ',

b. anaphoric binding, pronominal obviation of possessors by subject:

Atif $_{i}$ apnii $_{i} /$ us-kii $_{j / * i}$ behen-se lambaa hai Atif self.f/he-Gen.f sister-than tall be.Prs.Sg

'Atif ${ }_{i}$ is taller than self ${ }_{i}$ 's sister/his ${ }_{j / * i}$ sister.'

Without providing the actual examples, we note that pronominal than-phrases trigger Principle B effects with respect to other arguments. But non-subject arguments do not obviate pronominal possessors inside than-phrases. The binding possibilities of than-phrases are fully determined by its surface position with respect to other arguments of its predicate. (36a) and (37a) show us that if a pronominal co-argument precedes the than-phrase it cannot be coreferent with a proper name inside the than-phrase. When the relative order is reversed as in (36b) and (37b), coreference is possible.

(36) a. .....pron ${ }_{i} \ldots\left[\right.$ than Peter's $s_{i}$ sister].... : coreference is not ok

Sally-ne us-ko Peter-kii $_{j / * i}$ behen-se zyaadaa logõ-se Sally-Erg he-Dat Peter-Gen.f sister-than more people-with milvaa-yaa introduce-Pfv.MSg

'Sally introduced him $_{i}$ to more people than Peter's ${ }_{i}$ sister.'

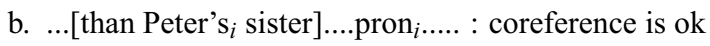

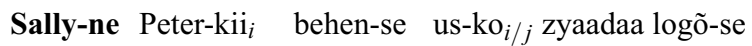
Sally-Erg Peter-Gen.f sister-than he-Dat more people-with milvaa-yaa introduce-Pfv.MSg

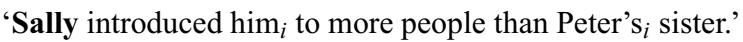

a. .....pron pr... $_{\text {than Peter's }}{ }_{i}$ sister] $\ldots .$. : coreference is not ok

Sally-kii foto us-ko $\mathrm{ko}_{i}$ Peter-kii ${ }_{j / * i}$ behen-kii foto-se zyaadaa Sally-Gen.f photo he-Dat Peter-Gen.f sister-Gen.f photo-than more logõ-ne dii people-Erg give.Pfv.f

'*More people gave $\operatorname{him}_{i}$ a picture of Sally than a picture of Peter ${ }_{i}$ 's sister.' 


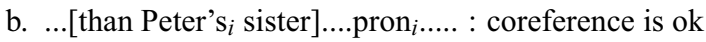

Sally-kii foto Peter-kii $i_{i}$ behen-kii foto-se zyaadaa Sally-Gen.f photo Peter-Gen.f sister-Gen.f photo-than more

$\operatorname{logõ-ne~} \quad$ us- $^{-k_{i}}{ }_{i / j}$ dii

people-Erg he-Dat give.Pfv.f

'*More people gave $\operatorname{him}_{i}$ a picture of Sally than a picture of Peter ${ }_{i}$ 's sister.' (ungrammatical in English, good in Hindi-Urdu)

Note that the binding behavior of the than-phrases follows directly from its surface syntax. We did not need to postulate covert clausal structure to explain its binding properties. The structural location of the boldfaced associate does not play any role in determining the binding possibilities of the than-phrase. In all the examples in (36) and (37), the associate precedes (and c-commands) the pronoun. Yet only some are good. We would like to add, without offering the relevant examples in the interest of conserving space, that scrambling the pronoun to precede the associate in variants of (36) and (37) does not change the binding possibilities as long as the relative order between the pronoun and the than-phrase is maintained.

To sum up, we have seen that the binding data that forced us to abandon the Direct Analysis for English is unavailable in Hindi-Urdu. The binding properties of the than-phrase in Hindi-Urdu are the same as those of ordinary PPs in Hindi-Urdu. They do not constitute an argument against the availability of the Direct Analysis.

\section{Scope of than-phrase-internal QPs}

The difference between Hindi-Urdu and English with respect to the availability of the Reduction Analysis and the Direct Analysis, respectively, is supported by the different interpretive possibilities available to than-phrase-internal QPs in the two languages. English phrasal comparatives allow -er to take scope over a than-phraseinternal QP. This can be seen in (38).

(38) More students read every syntax paper than every semantics paper.

a. than-phrase-internal scope:

[-er $[\lambda d .[d$-many students read every semantics paper $]]]$

$[\lambda d$. [ $d$-many students read every syntax paper]]

The number of students who read every syntax paper exceeds the number of students who read every semantics paper.

b. than-phrase-external scope: ???

[every syntax paper] $\lambda x$. [every semantics paper] $\lambda y$.

$[[-e r[\lambda d$. $[d$-many students read $y]]]$

$[\lambda d$. [ $d$-many students read $x]]]$

The least read syntax paper was still read by more people than any semantics paper. (paraphraseable as: every syntax paper was read by more students than every semantics paper.)

(Carl Pollard, p.c., paraphrase of $38 \mathrm{~b}$ suggested by Lisa Travis) 
It is not clear to us whether the reading corresponding to the QP taking scope over $-e r$, i.e. the reading indicated by (38b), is actually available. In other environments, such a reading seems to be quite freely available.

(39) Mary, a first grader, is taller than every third grader in our school.

a. unavailable: - er $>$ every

[[-er [ $\lambda d$. [every third grader is $d$-tall]]] [ $\lambda d$.[Mary is $d$-tall]]]

$(\approx$ Mary is taller than the shortest third grader. (assuming monotonicity))

b. available: every $>-e r$

[[every third grader] $[\lambda x$. [[-er [ $\lambda d .[x$ is $d$-tall]]] [ $\lambda d$.[Mary is $d$-tall]]]]] $(\approx$ For every third grader $x$, Mary is taller than $x$.)

(see Heim 2000, 2006, Larson 1988, Schwarzschild and Wilkinson 2002)

The apparent scoping-out behavior in (39) receives a very straightforward treatment within the Direct Analysis. The 3-place -er involved in the Direct Analysis combines with individual arguments and so any quantificational expressions need to QR out. But they can also be handled by a Reduction Analysis which can appeal to the fact that the interpretive restrictions noted for (39) also apply to Mary is taller than every third grader in our school is, a clausal comparative. Then whatever mechanism one uses to handle this clausal comparative can be used to handle (39) by a proponent of the Reduction Analysis.

When can a QP take scope inside a than-phrase and when must it (seem to) scope out? The generalization seems to be as follows.

(40) If a QP c-commands the site of degree abstraction, it must scope out. Otherwise it takes scope within the than-phrase.

a. degree abstraction c-commands QP: than-phrase-internal scope ok Craige assigned more students every paper by Egli than every paper by Klein.

b. QP c-commands degree abstraction: QP must scope out Craige assigned every first year student more papers than every second year student.

What this generalization tells us is that the need/ability to scope out of a than-phrase is not reducible to a subject/non-subject asymmetry. Instead it is only by making reference to the hierarchical relationship between the remnant and the site of degree abstraction within an abstract clause that this generalization can be stated. This by itself suggests the need for a Reduction Analysis in English.

We saw earlier that both a Direct Analysis and a Reduction Analysis can handle cases of QPs (apparently) scoping over -er. What about cases of QPs scoping below -er? Such cases are easy for a Reduction Analysis to handle. But not for a Direct Analysis, which forces any QPs to scope out. There is simply no other alternative. ${ }^{13}$ We now make a rather strong prediction. Given that we have argued that

\footnotetext{
${ }^{13}$ An alternative would become available if we had a higher order -er $r_{\text {high }}$ that combined with two quantifiers and a predicate of degrees and quantifiers.
} 
only the Direct Analysis and not the Reduction Analysis is available for phrasal comparatives in Hindi-Urdu, we predict that the judgments for the Hindi-Urdu counterpart of (38) will be the mirror image of the English (38) i.e. the scopingin reading in (38a) will be unavailable and the scoping-out reading in (38b) will be available. This is in fact the case. The Hindi-Urdu counterpart of (38) does not allow for the than-phrase-internal scope reading. The only interpretation available is the external scope reading.

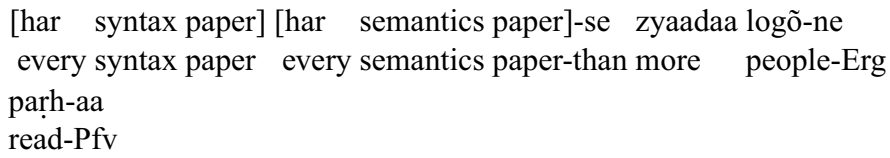

'More people read every syntax paper than every semantics paper.' every > -er: available; -er > every: unavailable

To get the than-phrase-internal scope, a clausal comparative must be used.

[jitne logõ-ne har semantics paper parh-aa] [us-se zyaadaa how.many people-Erg every semantics paper read-Pfv that-than more

logõ-ne har syntax paper parh-aa] people-Erg every syntax paper read-Pfv

'More people read every syntax paper than did every semantics paper.'

The scope facts thus provide additional support for our two claims. The first is that the Direct Analysis is available in Hindi-Urdu but not in English. This is why Hindi-Urdu allows/forces for than-phrase-internal QPs to scope out in (41) but English does not. The second is that the Reduction Analysis is available in English but not in Hindi-Urdu. The differential availability of the Reduction Analysis explains why QPs can scope-in in the English (38a) but not in the Hindi-Urdu (41).

\section{Handling Crosslinguistic Variation}

We have demonstrated that phrasal comparatives in English and Hindi-Urdu differ systematically. English phrasal comparatives involve a Reduction Analysis and block a Direct Analysis. The crucial data for this came from the binding properties of the remnant. Additional support came from the scopal properties of remnants. This means that English only has one -er, which is a 2-place -er.

Hindi-Urdu phrasal comparatives present a more complex picture. The binding data does not rule out the Direct Analysis while the Single Remnant Re-

(i) $\llbracket$-er $_{\text {high }} \rrbracket=\lambda Q_{(e t) t} \cdot \lambda \mathscr{D}_{d((e t) t) t} \cdot \lambda P_{(e t) t} \cdot \exists d[\mathscr{D}(P, d) \wedge \neg \mathscr{D}(Q, d)]$

Such a higher order -er would allow for a QP to take scope inside the than-phrase even with the Direct Analysis and would generate the desired meaning for (38). But this entry for -er would also allow for a QP to take scope within the than-phrase in cases like (39). Since in Hindi-Urdu neither is a possibility, we must conclude that $-e r_{h i g h}$ is not available. We speculate that even if -er $r_{\text {high }}$ were available, Beck's (1996)/Fox's (2000) constraint against higher order traces would make it unusable. 
striction and the scope facts argue against the Reduction Analysis. The Direct Analysis requires a 3-place -er. But we also need a 2-place -er to handle the more than $n$ cases and correlatives. Hindi-Urdu, then, has both a 2-place -er and a 3-place-er.

We would now like to explain why these languages differ in these ways. Why does Hindi-Urdu lack the Reduction Analysis, why does English lack the Direct Analysis, and why does English lack a 3-place -er? These are three questions but they actually reduce to two. The absence of a Direct Analysis in English follows directly from the absence of a 3-place -er. We have already provided a speculation concerning the first question. We think that the Reduction Analysis is unavailable for Hindi-Urdu phrasal comparatives because the environment in which the relevant reduction operations such as Gapping apply is systematically unavailable in Hindi-Urdu. Such operations apply to finite clauses in Hindi-Urdu and finite clauses cannot appear as a complement of a postposition, which is what the Hindi-Urdu $s e$ is. Consequently the Reduction Analysis is unavailable - not due to a specific constraint against it but due to independent properties of the language.

We now come to the last question: why does English lack a 3-place -er. The right way to answer this question, we believe, is to turn it around. Why does HindiUrdu have a 3-place -er? As far as we know all languages with comparatives have a 2-place -er. Why does Hindi-Urdu come to have a 3-place -er? Our suggestion is that the basic meaning of quantificational operators, one that is universally available, involves a 2-place semantics. Since -er is a degree quantifier, a learner of any language gets its 2-place version for free. 3-place -er, however, is only postulated if there is evidence in the form of data that requires a 3-place -er, data that cannot be handled by a 2-place -er. 3-place -er is extrapolated from the lexical entry for 2-place -er. In English, the relevant reduction operations are available and there is no evidence that forces the learner to assume a 3-place -er (and a Direct Analysis to go with it). But in Hindi-Urdu, the learner is unable to use the relevant reduction operations in the complement of -se/ 'than', forcing the learner to assume a 3-place -er and a Direct Analysis to go with it. In Hindi-Urdu, it is not possible to omit case-markers/postpositions even in the context of reduction operations. Therefore any phrasal comparative where the associate has an overt case marker/postposition on it constitutes positive evidence for 3-place -er. Such evidence is easy to come by in the primary linguistic data available to the learner.

In this context, we can ask why we do not seem to find corresponding 3place versions of quantifiers over individual such as every. What would such a 3-place quantifier look like? Mechanically applying the process by which we get the 3-place -er from the 2-place -er to derive a 3-place every from the standard 2-place every yields the following:

$$
\llbracket \text { every }_{3} \rrbracket=\lambda x \cdot \lambda P_{e e t} \cdot \lambda y \cdot[P(x) \subseteq P(y)]
$$

Our response is that every does not generally combine with individuals and so the syntax does not provide support for the postulation of a 3-place every. There are marginal cases like Every John likes pizza but here it is plausible that proper names like John of type $e$ can type-shift into an et meaning, allowing for us to retain the 2-place entry. This strategy cannot be used with phrasal comparatives where the 
corresponding type-shift would have to be from type $e$ to type $d t$.

\section{References}

Beck, Sigrid: 1996, Wh-constructions and transparent Logical Form, Doctoral Dissertation, Universität Tübingen, Tübingen, Germany.

Fox, Danny: 2000, Economy and Semantic Interpretation, No. 35 in Linguistic Inquiry Monographs. MIT Press, Cambridge, Massachusetts.

Heim, Irene: 1985, 'Notes on Comparatives and Related Matters'. Unpublished manuscript, University of Texas at Austin.

Heim, Irene: 2000, 'Degree Operators and Scope', in Proceedings of SALT X, 4064. Cornell Linguistics Club, Cornell University, Ithaca, NY.

Heim, Irene: 2006, 'Remarks on Comparative Clauses as Generalized Quantifiers'. Massachusetts Institute of Technology manuscript.

Larson, Richard: 1988, 'Scope and Comparatives', Linguistics and Philosophy 11, $1-26$.

Lebeaux, David: 1990, 'Relative clauses, licensing, and the nature of the derivation', in Proceedings of NELS 20, 318-332. GLSA, Amherst, Massachusetts.

Lechner, Winfried: 2001, 'Reduced and phrasal comparatives', Natural Language and Linguistic Theory 19, 683-735.

Lechner, Winfried: 2004, Ellipsis in Comparatives. Mouton de Gruyter, Berlin.

Merchant, Jason: 2006, 'Phrasal and clausal comparatives in Greek and the abstractness of syntax'. Unpublished University of Chicago Manuscript.

Nevins, Andrew and Pranav Anand: 2003, 'Some AGREEment matters', in G. Garding and M. Tsujimura (eds.), Proceedings of WCCFL 22, 370-383. Cascadilla Press, Somerville, MA.

Pancheva, Roumyana: 2006, 'Phrasal and Clausal Comparatives in Slavic', in Formal Approaches to Slavic Linguistics 14: The Princeton Meeting.

Pancheva, Roumyana: 2007, 'Than'. Handout of Talk Presented at GLOW XXX, Tromsø, April 14.

Richards III, Norvin W.: 1997, What Moves Where When in Which Language?, Doctoral Dissertation, Massachusetts Institute of Technology, Cambridge, Massachusetts.

Schwarzschild, Roger and Karina Wilkinson: 2002, 'Quantifiers in Comparatives', Natural Language Semantics 10, 1-41. 